\title{
Strategic planning for management of information and electronic communication in healthcare sector: Story of the North-Western Province
}

Dr. W. M. A. Wijekoon MBBS, MSc (Biomedical Informatics)

Provincial Health Informatician, Provincial Department of Health Services - North Western Province, Sri Lanka E-Mail address: aawijekoon@gmail.com

Dr. R. M. S. K. Rathnayake MBBS, MSc (Medical Administration)

Provincial Director of Health Services, Provincial Department of Health Services - North Western Province, Sri Lanka

E-Mail address: smnrtnk@gmail.com

Sri Lanka Journal of Bio-Medical Informatics 2013;4(1):3-6

doi: http://dx.doi.org/10.4038/sljbmi.v4i1.5674

\begin{abstract}
In the recent past, several attempts to incorporate computer based solutions and electronic communication into the flow of data and analysis of information in the government healthcare sector in Sri Lanka could not be sustained or successfully replicated. This is true for the Provincial Department of Health Services of the North Western Province as well.

Therefore the need for strategically planned background work was identified as a priority before developing on complex individual information systems within the healthcare sector of the North Western Province. The provincial department successfully implemented a medium term strategic plan empowering the department towards incorporating electronic communication and computerised solutions appropriately and optimally while ensuring safety and privacy of the care recipients.
\end{abstract}

Keywords - Health Information; Strategic Plan; Healthcare; Communication; Sri Lanka; Provincial Council

\section{Introduction}

Informed decision making is vital for the health care sector. In curative care, community health and in administration, Information and Communications Technology could be used to support decision making by collecting and processing data into information. Several attempts have been made in the recent past to adopt ICT in different data flows of the Provincial Department of Health Services - North Western Province (PDOHS-NWP) but could not be sustained.

The need for directing the PDOHS-NWP towards using information systems and electronic communication effectively was identified. This was expected to facilitate improvement of quality and efficiency of healthcare delivery while ensuring safety and confidentiality of care recipients $^{(1)}$.

In 2011, PDOHS-NWP declared a three year strategic plan for management of information and electronic communication. This was based on the draft version of the National eHealth Strategic Plan of the Ministry of Health ${ }^{(2)}$. This was aimed at completing the ground work in a way that future computer based information systems could be sustained within the healthcare system.

\section{Provincial Department of Health Services - North Western Province}

With the 13th amendment to the constitution, in 1987 the government devolved many powers to the then established Provincial Councils. According to the ninth schedule added to the 
constitution through the 13th amendment; health is included in both the Provincial Council's List and the Concurrent List making it a subject to be handled both by the Government and the Provincial Councils. Provincial Departments of Health Services were established for each Province headed by a Provincial Director of Health Services under the respective provincial councils. PDOHS-NWP was established taking over the administrative control of two Regional Directors of Health Service Divisions of Kurunegala and Puttalama. This Provincial Department has about 200 institutions under it including 58 hospitals, 87 Primary Medical Care Units and $34 \mathrm{MOH}$ Divisions.

\section{Strategic plan for management of information and electronic communication}

\section{Vision}

Delivery of high quality healthcare through informed decision making.

\section{Mission}

To facilitate informed decision making in the healthcare sector within the North-Western Province of Sri Lanka by managing information, electronic communication and computerised solutions appropriately and optimally while ensuring safety and privacy of the care recipients.

\section{Objectives}

1. To build management capacity

2. To improve electronic communication

3. To facilitate streamlining and standardisation

\section{Success of the implementation}

Most of the activities of the Strategic Plan were started during the first year of implementation and many activities have been completed successfully ${ }^{(3)}$. Major activities completed are success below.

\section{To build management capacity}

a. Health Information and Research Unit

A small ICT unit was upgraded to cover the broader scopes of health information and research under a medical officer qualified in health informatics. The unit was provided with physical resources including a computer laboratory with 10 computers. Currently the unit has a staff of five.

b. In-house training on Health Information and ICT

Training needs of the staff were identified, prioritised and categorised. Curricula were developed for each identified category. Regular, on the job training programmes are being conducted on demand at the computer laboratory.

C. Internet access guidelines

Although internet connectivity was provided for institutions to enhance productivity and efficiency of service, unguided use of internet by the staff had resulted in decreased productivity. Such guidelines and monitoring is in force in the corporate sector but is lacking 
in the government sector. A detailed set of guideline were issued to enlighten the staff on the appropriate use of the internet.

\section{To improve electronic communication}

A. Universal and cost effective voice connectivity

Voice connectivity is essential for all the healthcare institutions. $40 \%$ of the institutions under the Provincial Department did not have voice connectivity as at end of 2011. Subsequently, Sri Lanka Telecom PLC (SLT) generously agreed to provide free telephone connections to all the institutions. This made NWP the first province in Sri Lanka with a phone line to all government healthcare institutions.

A special package was given by the SLT to the department waiving off some charges. A master bill for the entire department simplified the bill payment process.

B) Proper use of electronic mail for official communication

Ensuring accountability, authenticity and adherence to the proper channel of communication in using electronic means for official transaction of documentation was identified as a timely need. As an initial step, training sessions were conducted for heads of the institutions and the units and official e-mail accounts under the format of <user_name>@healthdept.nw.gov.lk were issued to the trained users.

Postal units of the large institutions are also being modernised facilitating those units to handle e-mail and facsimile communication.

\section{To facilitate streamlining and standardisation}

A. Making the department free of pirated software

Use of pirated software had been the de-facto norm in Sri Lanka probably due to lack of awareness and lack of interest in the problem. The department has decided to have zero tolerance on pirated software. Following steps have been taken to work towards achieving the desired states.

- All new computers to be bought only with genuine operating systems.

- Free and Open Source Software (FOSS) to be distributed to replace pirated versions of commonly used commercial software.

- Training the staff on copyright and hands on training on the use of FOSS alternatives for commonly used commercial software (Table 1).

\begin{tabular}{|l|l|l|}
\hline FOSS Software & Use & Commercial software \\
\hline Libre Office & Office suite & Microsoft Office \\
\hline GIMP & Image Editing & Adobe Photoshop \\
\hline Inkscape & Graphics editor & CorelDRAW \\
\hline Dia & 2D Diagramming software & Microsoft Visio \\
\hline PSPP & Statistical analysis & SPSS \\
\hline
\end{tabular}

Table 1. FOSS alternatives for commonly used commercial software 
B. Keyboard standards and encoding standards

Encoding keyboards for using Sinhala and Tamil scripts has been standardise for several years, but it had not been universally adopted in the Provincial department. Following steps were taken to comply with standards.

- All new desktops to be bought with trilingual keyboard configuring to SLS 1326:2008 standards ${ }^{(4)}$.

- Issue of clear instruction to use unicode standard in any comment in Sinhala language to comply with 1134:2004 ${ }^{(5)}$ or Tamil Language.

- Training on upgrading the Operating System and other software of old computers to make those compatible with unicode standards and $24 \times 7$ over the phone technical support to the staff.

- Training the office staff on typing Sinhala text using standard keyboard and Unicode compatible fonts.

\section{Conclusion}

The PDOHS has laid the foundation for the implementation of information systems that uses ICT in the healthcare sector in the Province. There are more to be done to improve human resources, physical resources and guidance on the field of ICT and health information to ensure that current and future endeavours are successful and sustained. This could be achieved if strategically planed, even in a resource poor setting.

\section{References}

1. Provincial Department of Health Services - NWP. Strategic Plan for Management of Information \& Electronic Communication 2012-2014. Revision 3, Sri Lanka: Provincial Department of Health Services - North Western Province, 2013.

2. National eHealth Technical Committee. National eHealth Strategic Plan (Draft). Version 2.8.2, Sri Lanka : Ministry of Health, 2012.

3. Provincial Department of Health Services - NWP. Annual report 2012; Implementation of the Strategic plan for management of information and electronic communication. Provincial Department of Health Services - North Western Province, 2013.

4. Sri Lanka Standards Institution. Tamil Character Code for Information Interchange. Colombo, Sri Lanka: Sri Lanka Standards Institution, 2008.

5. Sri Lanka Standards Institution. Sinhala Character Code for Information Interchange. 2nd Revision Colombo, Sri Lanka: Sri Lanka Standards Institution, 2004. 